\title{
EN BUSCA DEL SÍ MISMO PERDIDO DEL DASEIN: UN DIÁLOGO ENTRE KAFKA Y HEIDEGGER EN TORNO A LA CUESTIÓN DE LA CULPABILIDAD Y LA MISMIDAD
}

\author{
IN SEARCH OF LOST SELFHOOD OF DASEIN: A \\ DIALOGUE BETWEEN KAFKA AND HEIDEGGER \\ CONCERNING THE ISSUE OF GUILT AND \\ SELFHOOD
}

\author{
Juan José GARRIDO PERIÑÁN \\ Universidad de Sevilla*
}

\begin{abstract}
Resumen: La presente meditación constituye un intento por pensar, desde una situación existencial extraída de la novela de Kafka "El Proceso", un horizonte fenomenológico, de rescate y salvamento de la posibilidad como eminente modo de ser del existente, a fin de ganar una claridad del problema de la conciencia, a través de los análisis vertidos por Martin Heidegger en su libro Ser y Tiempo, en concreto en la Segunda Sección del Tratado. Para ello se analiza el fenómeno de la culpa como promesa para que el existente, llegado el caso, pueda conquistar su propio ser, su sí-mismo. Se concluye acudiendo a la máxima délfica: ¡conócete a ti mismo!, en cuanto representa simbólicamente el camino seguido para determinar el objetivo principal de nuestra meditación: elaborar un horizonte fenomenológico de la mismidad del Dasein.
\end{abstract}

\footnotetext{
* Investigador Predoctoral FPU en la Universidad de Sevilla. Departamento de Metafísica Corrientes Actuales de la Filosofía, Ética y Política. C/ Camilo José Cela S/N 41018, Sevilla (España). Correo electrónico: jjgarper@us.es. Esta meditación se realizó gracias al soporte otorgado por el Ministerio de Educación, Cultura y Deporte (MECD), bajo el Programa FPU, con la referencia FPU13/00375.
} 
Palabras clave: Fenomenología, Heidegger, culpa, Kafka, mismidad.

АвsтRACT: The current meditation is an attempt to think a phenomenological horizon from an existential situation taken from Kafka's novel: "The Trial". This phenomenological horizon tries to recover the possibility as an eminent mode of existing's being, in order to gain clarity regarding the problem of consciousness. Consciousness is analyzed using Martin Heidegger's book "Being and Time", particularly its Second Section. In order to achieve this, the phenomenon of guilt as a promise so that the existing, when necessary, can conquer its own being, its self, is analyzed. This analysis concludes using the Delphic proverb "Know yourself!", as this proverb symbolically represents the path followed to determine the main purpose of our meditation: to develop a phenomenological horizon of selfhood of the Dasein.

KeYwords: Phenomenology; Heidegger; guilt; Kafka; selfhood.

\section{Introducción: La necesidad de la mirada fenomenológica. Un acercamiento entre Kafka y Heidegger}

"Seguramente habían calumniado a Joseph K., pues, sin que nada malo hubiera hecho, fue detenido una mañana” (Kafka, 2003: 8-9). De este modo, tan enigmático, comienza una novela póstuma, escrita en alemán, del literato checo Franz Kafka. El lector, si atiende a la verosimilitud que toda novela pueda pretender tener, podría quedar sorprendido al observar que, en este caso, el protagonista de la novela es detenido, y, por tanto, acusado, sin saber por qué. El lector se encontrará con una condena sin principio de razón suficiente ${ }^{1}$. Stricto sensu, lo

\footnotetext{
${ }^{1}$ Las referencias que ligan la temática de la culpabilidad, y la obra El Proceso, con parte del pensar de Heidegger se han encontrado, principalmente, en 2 libros (Carmann, 2003: 290291 y Adrián, 2016: 59-60). Los análisis que realizan ambos autores son someros, pues, en ningún caso, esta temática, constituye el hilo conductor de sus respectivos libros. Nuestra meditación es heredera, en parte, de la contribución realizada por Carmann y Adrián, pero, en ningún caso, se constituye como un ejercicio de mimesis filosófica, sino que hemos intentando explicitar y desarrollar la cuestión en toda su posibilidad. Conviene, empero, no olvidar la aportación de Wiemel (1991: 17-38), quien conecta parte de la obra de Heidegger Ser y Tiempo con la novela de Kafka El Proceso, comprendiendo el problema de K. -el protagonista- como una problemática de índole ontológica. Grosso modo, lo que subyace en la novela de Kafka, en particular, pero en todo acto narrativo, en general, y según Wiemel, es un fenómeno respectivo a la temporalidad. El acto narrativo, circunscrito como forma temporal de ejecución de la existencia humana, se ha de comprender siempre ligado al tiempo. Por tanto, el acto narrativo es, eo ipso, un acto de temporalización de la vida humana. Nuestra meditación recogerá en parte el testigo dejado atrás por Wiemel, en lo concerniente a la
} 
que sucede en la novela es un "encontrarse" [sich-befinden] con la condena, en el sentido filosófico que le dio Heidegger al mismo: la condena, la acusación de culpabilidad de Joseph K. "se da" [es gibt], sin más. Este hecho nos tiene que poner en alerta, a fin de hacernos cambiar de actitud, pues no es lo mismo que comprendamos literariamente la novela, y el fenómeno de la acusación de la culpabilidad, que hacerlo al modo de la filosofía, en nuestro caso, desde el horizonte de la fenomenología ${ }^{3}$. Que sea fenomenológicamente comporta, al menos, dos cosas: realizar epojé y reducción ${ }^{4}$, pero también que tengamos una actitud de "dejar-ser" [sein-lassen] al fenómeno, en la legitimidad propia de su darse. Tal y a la manera de Husserl: ¡ a las cosas mismas! [zu den Sachen selbst']. La fenomenología trata de poner el énfasis en el modo de aparecer de las cosas,

preocupación temporal, pero constituirá, como se observará en las siguientes páginas, un ejercicio independiente de apropiación filosófica, por cuanto el objetivo final es, aunque sea de modo propedéutico, dejar preparada la pregunta por el sí mismo del Dasein.

2 El problema del encontrarse, entendido como "disposición afectiva" [Befindlichkeit], le interesó a Heidegger desde sus primeros cursos en la Universidad de Friburgo, tal y como dicta el curso de 1920/21 (1995: 42): "Algo es histórico cuando la materia de lo inmediatamente experienciado provoca en nosotros un determinado efecto afectivo, cuando nosotros nos vemos afectados por él". ["Etwas wird historisch dann, wenn der Stoff des unmittelbar Erfahrenen in uns eine bestimmte Gefühlswirkung auslöst; wenn wir von ihm getroffen werden"]. Véase, del mismo modo (Heidegger, 2002: 57, 102, 104, 119, 121, 135, 141, 144, 268 y 279). A partir de ahora, asumimos las traducciones de los textos de Heidegger. Cuando se considere menester, en orden de ganar una claridad conceptual, se acompañará la traducción con el original alemán.

${ }^{3}$ Cuando nos disponemos a comprender un determinado fenómeno, nuestra actitud puede ser múltiple, ya que podemos comprenderlo desde un sentido histórico e historiográfico, en este caso actuaremos históricamente; o podemos comprenderlo atendiendo a un análisis sintáctico, para este caso, entonces, nos comportaremos como filólogos. Pero, ¿cuál es el comportamiento por excelencia filosófico? Creemos que es el propio de la fenomenología. Piénsese lo que dice Heidegger en Sein und Zeit sobre la posibilidad de la ontología si solo si como fenomenología (2002: 35): "Fenomenología es el modo de acceso y de determinación evidenciante de lo que debe constituir el tema de la ontología. La ontología sólo es posible como fenomenología". ["Phänomenologie ist Zugangsart zu dem und die ausweisende Bestimmungsart dessen, was Thema der Ontologie werden soll. Ontologie ist nur als Phänomenologie möglich"].

${ }^{4}$ El proceso fenomenológico de la epojé hace referencia a un cambio de actitud en el acceso a las cosas, principalmente, en contra de la actitud natural y psicologista que, de continuo, nos vemos absorbidos. Husserl la menciona por vez primera en 1905, en los Seefelder Blätter (1966: 253). En cambio, la reducción era el reducto fenoménico que queda cuando se hace epojé del fenómeno en cuestión. Para Husserl, la reducción trascendental es el último nivel de la reducción, pues antes están: la reducción gnoseológica y eidética (1977: 62-63 -reducción gnoseológica-, 68 y 103-107 -reducción eidética-) y (1959: 71 -reducción trascendental-). El objetivo, muy grosso modo, de la reducción trascendental es desvelar el papel constituyente, fundante, de la subjetividad trascendental. 
antes que determinar la quiddidad de aquello que es. Por esta razón, la fenomenología trata con modos de ser, no con cosas. Del mismo modo, un mirar fenomenológico tiene que dejar de lado la verosimilitud de la historia narrada en la novela, debe saber poner entre paréntesis, aparcarlo, si la novela fue póstuma, incluso si la escribió Franz Kafka: ¿de verdad importaría saber si fue escrita por él, o, más bien, lo vital es adentrarnos en el fenómeno que vertebra la prosa: la culpabilidad del protagonista?

Haciendo estas advertencias, pasaremos a un análisis fenomenológico del fenómeno de la conciencia, tomando como ejemplo la obra kafkiana, para esclarecer el sentido ontológico de la culpa como una advertencia, y posibilidad, de un conocimiento del sí mismo, lo que otrora, por el filosofar moderno, fue llamado subjetividad, sujeto o cogito. Pero nosotros lo comprenderemos de otro modo.

\section{Análisis fenomenológico de la situación existencial partiendo del caso de Joseph K.: conciencia, culpa, Ilamado de la conciencia. Hacia el horizonte del sí-mismo del Dasein}

Lo que le acontece a Joseph K. es que no sabe de qué se le acusa, esto es, no es capaz de ser consciente de lo que le ocurre. El pensamiento moderno, muchas veces entendido como la época de la mayoría de edad de la subjetividad humana, se puede pensar como un esfuerzo de búsqueda de un fundamento que explicara la realidad del mundo, por aquel tiempo un mundo viejo casi desacralizado, en el fundamento del cogito ergo sum. Heidegger lo piensa como la época en la que el mundo se ha hecho imagen (Cfr. 1977: 75-114), a saber, cuando el sujeto humano se ha convertido en subiectum y, a partir de su propia inmanencia epistemológica, se convierte en el fundamento del mundo, en el árbitro que "pone" $[$ setzt] ahí la "objetualidad" del ente, su objetividad. El sujeto, more modernidad, es el esfuerzo de una voluntad cuyo fin es "poner(contra)-ahî" [Gegenstand] el ente

\footnotetext{
${ }^{5}$ Heiddeger está pensando en Kant, en el concepto de apercepción trascendental (Kant, 2005: 156): “... el nuestro -el entendimiento- sólo puede pensar, y debe de buscar la intuición desde los sentidos. En relación, pues con la variedad que me ofrecen las representaciones en una intuición, tengo conciencia de la identidad del yo, ya que las llamo a todas representaciones mías, que forman, por tanto, una sola. Ello equivale a decir que tengo conciencia a priori de una ineludible síntesis originaria de apercepción. A esta unidad han de estar sometidas todas las representaciones que se me den, y a ella han de ser reducidas mediante una síntesis".
} 
llamado mundo ${ }^{6}$. El pensar moderno, se quiera o no, es un pensar de la conciencia. Para la mayoría de los modernos, la "conciencia" [Bewußtsein] es sinónimo de fundamento, evidencia y verdad. Este ejemplo se ve reflejado palmariamente en la Tercera Meditación cartesiana, cuando el mismo Descartes hablando en primera persona, para captar la verdad del yo-pienso, tiene que hacer un gran ejercicio de epojé fenomenológica, desconectando al sujeto de su mundo, de los sentidos y hasta de su cuerpo (Cfr. Descartes, 1977: 31-44) ${ }^{7}$. ¿Podría leerse la novela de Kafka, en la imposibilidad que tiene el protagonista por saberse, como un antagonismo de esta conciencia moderna, ilustrada? En nuestra opinión, esta dicotomía, es un error. En primer lugar, la novela está inacabada y, por ende, no hay con rigor un cierre ${ }^{8}$. En segundo lugar, no hay una resolución a la culpabilidad que arrastra K., sino que esta culpa es una culpa intestinal, pertenece a la misma estructura del ser-en-el-mundo del protagonista. Es una culpa ontológica, no accidental. Por último, en tercer lugar, es una culpa en la que uno no puede salir, ponerse fuera de ella, a fin de conocerla objetivamente, "sobrepasarla" [es überholen], dominarla, calcularla (Cfr. Heidegger: 1976: 117). Por eso, la implícita conciencia presente en la culpabilidad de K. la pensamos conforme al análisis que dio Martin Heidegger en su libro, quizás, más conocido: Ser y Tiempo, en concreto en la II Sección del Tratado (\$\$.45-85), donde el filósofo, una vez desplegado un análisis fenomenológico-hermenéutico de la situación del Dasein ${ }^{9}$,

\footnotetext{
${ }^{6}$ Gegenstand es unas de las traducciones al español de objeto. Para Heidegger, Gegenstand viene a traducir la expresión latina objectum y se diferencia de Objekt en que Objekt es pensado como cualquier objeto temático, mientras Gegenstand es el objeto temático determinado previamente como quididad, puesto, predispuesto y a disposición del subiectum.

${ }^{7}$ Nótese que no se está teniendo en cuenta la posibilidad de que el cogito, además de poder constituir un mecanismo de socavación del campo de fenomenalidad, por cuanto petrifica la vivencia, pueda ser tomado como un principio inmanente que resaltase la necesidad del darse mismo de la intuición y, en este sentido, no constituyera una herramienta constrictiva con el ámbito de la fenomenalidad. Una perspectiva así, tendría que confrontar las formas de hacer fenomenología de Husserl y Heidegger. Esta temática ha de quedar aparcada para desarrollarla en otro lugar.

${ }^{8}$ La idea de cierre la pensamos junto a la idea de comienzo y la idea de comienzo junto a la posibilidad de instaurar un orden, tal y como puede ser pensado el fundamento de la subjetividad por la vía moderna. Para ampliar esta temática recomiendo la interpretación de Sloterdijk de la modernidad como ontología cinética (2001) y (Garrido-Perinán, 2012: 99-112).

9 Bien es verdad que por Dasein se puede verter al castellano la palabra "existencia", pero -según pensamos- esta traducción no le hace justicia, si de verdad se quiere explicitar propiamente lo que quiere mentar Heidegger. Dasein es el ente ontológico que, entre los demás entes (ónticos) que "están-ahî" [Vorhandenheit], le pertenece algo así como un "ahî" $[D a]$. Lo que sea el "ahí" es complejo de entender en el "camino" [Weg] heideggeriano, ya que es un rótulo bastante utilizado en su obra y que, a lo largo de los años, ha sufrido una evolución en su significado (Cfr. Garrido-Periñán, 2015a: 302-320). Lo importante es que Da es el lugar
} 
quiere preparar el terreno para la explicitación del horizonte del tiempo como dominio-trascendental donde se despliega el sentido del ser del ente, "aquello a partir de lo cual en general el Dasein entiende e interpreta implícitamente algo así como el ser" (Heidegger, 2002: 17) ${ }^{10}$. En particular, centraremos nuestra atención en los parágrafos comprendidos entre el cincuenta y cuatro y sesenta. En esos parágrafos, se intenta esclarecer la posibilidad de un desvelar completo del ser del Dasein, a través del fenómeno de la conciencia -con un análisis de la culpabilidad incluido-, a fin de la obtención, por parte del existente, de un "estado de apertura" [Erschlossenheit], óptimo, pleno, sin fisuras y subterfugios.

Pensamos que una lectura atravesada por la interpretación ontológica que hace Heidegger de la conciencia, la culpa y el estado de resuelto, ayudaría a comprender esa culpa radical que persigue al protagonista de la novela El Proceso de 1925.

\subsection{La conciencia práctica de la vida fáctica: Gewissen y Bewußtsein}

Hay, en Ser y Tiempo, dos vías principales para ganar el "estado de propiedad" [Eigentlichkeit] y del "ser-entero" [Ganzsein] del existir ${ }^{11}$. Una de ellas pasa por un apoderamiento del ser-para-la-muerte, en una "aceptación" [Annahme] de tu constitución mortal y de tu relación inminente con ella, que te permita ser desde la posibilidad que define tu vida. La otra vía es, complementaria con la primera, "estar-despierto" [wach-sein], ser consciente de tu propia finitud, expresada en tu "ser-culpable" [schuld-sein], para que, una vez aceptada la nihilidad que compone tu propio ser en tanto culpable, ganar un decisión genuina, propia,

donde acontece la apertura del mundo del ente que existe, el Dasein. Por tanto, el Dasein es el ente que, con su modo de ser: la ex-sistencia, siempre está proyectado en infinitas posibilidades, que lo limitan y lo definen. El Dasein es el ente que tiene una preeminencia ontológica porque, justamente, es el único ente que se pregunta por algo así como un ser. Valga su referencia en el opus magnum heideggeriano: (2002: 7, 11-15, 15-19, 37-38, 41-45, 50-63, 84, 114-117, 134-135, 143-144). Para ver, por lo demás, cómo este Dasein no ha de ser definido en tanto animal rationale, esto es, como subiectum (Cfr. Heidegger: 1976: 313364).

${ }^{10}$ Grosso modo, la meta del Tratado era la elaboración de un horizonte temporal, re-obtenido por mor de una hermenéutica de la temporalidad [Zeitlichkeit] mundana del Dasein, que sirviera como un "trascendental" desde el que comprender el ser del ente en general, en tanto temporalidad [Temporalität].

${ }^{11}$ Tómese el existir en relación en lo expresado en la nota 9, esto es, como Dasein. 
llamada, entre otras cosas, "estado de resuelto" 12 [Entschloßenheit $]$. De entre estas dos vías, nosotros vamos a centrarnos, sobre todo, en la segunda, en virtud del tratamiento que se ejerce sobre la culpa. Pero, antes, es menester hacer unas cuantas referencias semánticas y metodológicas, a saber, conciencia para Heidegger es Gewissen, que vendría a ser esa instancia que nos mueve a actuar, a ser, en general, y que dista de esa conciencia teórica denominada Bewußtsein ${ }^{13}$. Conciencia es para Heidegger un principio cinético de resolución de vicisitudes cuyo cometido último es desvelar un modo referencial y "ejecutivo" [Vollzug] para que el existente pueda vivir propiamente. El vivir propio, de alguna manera, tiene que ser una "atestiguación" [Bezeugnung], en términos fenomenológicos, se le tiene que dar al Dasein en su vida, en su existencia. De lo contrario, tendríamos que suponerlo, crearlo, inventarlo, es decir, no acontecería y no sería fenomenológico.

Por otro lado, la metodología usada para llegar hasta aquí se produce como retorsión del método empleado en la I Sección del Tratado: en la II Sección de lo que se trata es partir del estado de propiedad para, a través de un análisis de la "temporalidad del Dasein" [Zeitlichkeit], en su modalidad de temporalidad impropia, reconducir y ganar un sentido original y genuino de esta misma temporalidad impropia del Dasein, en la que éste vive cotidianamente, justo lo que con tesón, y desde un gran calado hermenéutico, se había analizado en la I Sección. Con esta anotación metodológica, Heidegger cumple con su idea de circularidad hermenéutica, es decir, de la imposición de toda facticidad sobre el futuro, de todo haber-sido sobre el "seré". Este ámbito es la existencia, el lugar donde vivimos.

\footnotetext{
${ }^{12}$ En las siguientes líneas definiremos con más explicitud a qué se refiere Heidegger con el estado de resuelto (Cfr. infra.: 3.2. y 3.3.).

${ }^{13}$ Gewissen ha sido relacionada por Gadamer con la phronesis aristotélica (1987: 244-247 y 1983: 31). Para Heidegger, el uso de este término no se debe a justificaciones formales, sino que Gewissen, en virtud de su etimología en tanto "saber en conjunto" o "saber del conjunto", hace referencia al actuar, a una actuación que es siempre relativa a una situación o circunstancia, aquí y ahora. Esto le permitió a Heidegger, por de pronto, insertar un sentido de temporalidad a la acción humana (Cfr. 1992: 21-187). Desde el otro sentido de la palabra conciencia como Bewußtsein, este término se emplea para designar ese "foro interior" que, por ejemplo, es mentado por Kant, cuando quiere significar el principio que nos mueve a la acción. Para una extensión de esta problemática (Cfr. Kant, 2004: 2003). Es pertinente el trabajo de (Hübsch, 1995). Por último, para una ampliación de la problemática, en relación con Heidegger (Cfr. Adrián, 2016: 41-68).
} 


\subsection{La existencia y la posibilidad de recuperar la elección sobre el propio ser}

Recordemos que el personaje de Kafka, desde su imputación, no se re-cono$\mathrm{ce}^{14}$. En innumerables ocasiones, como por ejemplo cuando está en el banco, donde trabaja y tan eficiente ha sido, sus acciones cambian, se transmutan, quedan muy alejadas de todas esas acciones que K., cuando era K., es decir, antes del Proceso, realizaba. ¿Qué es lo que sucede aquí? Hay un rigor que solo la fenomenología enseña y que consiste en atenerse al modo en el que la cosa, el fenómeno, se da. Para este caso, tenemos que partir, si de verdad queremos preguntar sobre quién es K., de una atestiguación. Heidegger, en su opus magnum, reclama esta necesidad, a saber, que el Dasein, desde y para con su existencia, se tiene que topar con una indicación de un determinado ser-propio, con respecto a su mismo ser (Cfr. Heidegger, 2002: 114-117). Habría que recordar, aunque sea ligeramente, al menos dos cosas: hay dos modos de ser del ente, que quedan resumidos en el "estar-ahî" [Vorhandensein] y la "existencia"15. Ambos modos son formas que un determinado ente tiene de ser o existir. Lo curioso es que, para Heidegger, el único ente que existe es el Dasein, en la medida en que puede tomarse a sí mismo, y preguntarse por su ser. Esto queda ejemplarizado en el curso de 1925: Prolegómenos para una historia del concepto de tiempo, con la expresión ese "quedar afectado al preguntar por lo preguntado" (1979: 200) ${ }^{16}$. El Dasein es el único ente que vive "entregado" [überantwortet] en la posibilidad de la pregunta; más aún, la posibilidad de la pregunta radica en que el Dasein vive afectivamente dispuesto (abierto-templadamente) en su modo de ser. En este caso, para distanciarse de corrientes filosóficas que abogan por la autenticidad ética o moral de una determinada vida ${ }^{17}$, la atestiguación que encuentra el Dasein

\footnotetext{
${ }^{14}$ Compárese con esto que dice Hegel (1980: 26): "Lo conocido, por el mero hecho de ser conocido, no es todavía reconocido". ["Das Bekannte überhaupt is darum, weil es bekannt ist, nicht erkannt”]. La conciencia apunta a una apropiación. Desde qué sentido lo veremos a lo largo de nuestra meditación.

${ }^{15}$ Esta diferencia se hace más ilustrativa en la descripción de los diferentes modos de ser entre Dasein, animales y plantas (Cfr. Heidegger, 1983: 261-264 y 274-532).

${ }^{16}$ Compárese con lo expuesto en Ser y Tiempo (2002: 7): "A este ente que somos en cada caso nosotros mismos, y que, entre otras cosas, tiene la posibilidad de ser del preguntar, lo tomamos nosotros con el término Dasein". Del mismo modo, en referencia al modo de ser del "estar-ahî" (Cfr. Ibid.: 267).

${ }^{17}$ Habría que recordar la pregunta de J. Beaufret: para cuándo escribe usted una ética, que motivó la redacción del escrito de 1946 Carta sobre el humanismo (Cfr. 1976: 313-364). Es sabido que Heidegger, a lo largo de su obra, no da una respuesta satisfactoria, sobre todo si se pretende, como respuesta, una afirmación categórica y normativa, que nos indique cómo
} 
sobre su posible ser-propio siempre es una "manera de existir" [Weise zu existieren], y no una propiedad que, como quiddidad, le pertenezcan al ser del Dasein. La propiedad de la existencia de todo Dasein radica en ser una posibilidad. Pero, entre tanto, ¿qué quiere mentar que sea esta una posibilidad? Para decirlo al modo negativo: que no es algo necesario, algo que se llegue y del que nunca más podamos cambiar, la propiedad de la existencia se configura así como una "modificación" [Verwandlung] existencial del Uno. "El Uno" [das Man] es el modo, según el cual, por el que a través, cotidianamente, cual reflejo, el Dasein se entiende a sí mismo, actuando como los demás, vistiéndose como los demás se visten, es decir, para resumir, siendo el "uno-mismo"18 [man-selbst]. A nosotros nos interesa aquí enfatizar el entramado del uno, porque, en la novela de Kafka, este uno se ve constantemente simbolizado en la estructura de la burocracia, jueces, enfermeras, celadores, etc., que, de continuo, parecen querer ayudar a K. Para Heidegger, del mismo modo, el uno ayuda ${ }^{19}$ al Dasein a sentirse unomismo, a ser alguien.

Empero, tendríamos que poner nuestra atención, en un hecho notorio, muchas veces soterrado y pasado de largo: ¿̇e qué se ve privado K.? De la posibilidad de tomar una "elección" [Wahl]. Joseph K. es un individuo inhabilitado para ser, o sea, para decidir. Heidegger lo vio muy bien, sobre todo, al comprender que toda posibilidad de ser-propio ha de pasar por la "recuperación de una elección" [Nachholen einer Wahl], una elección que ha sido, constantemente, perdida por el fáctico "soy-sido" [bin-gewessen] del uno. Esto es lo que en el argot heideggeriano se llama atestiguación de "poder-ser-sí-mismo" [Selbstseinkönnen] (Cfr. 2002: 268). En este sentido, podríamos explicar la novela de Kafka como

vivir, cómo comportarnos. Si es verdad que la fenomenología, al menos la heideggeriana, trata sobre cómo son las cosas, y nunca tiene como finalidad determinar qué son, lo importante sería, entonces, transparentar la situación en la que de continuo estamos, no determinar un modo de vida auténtico que, por otro lado, nos reificaría. Por motivos de extensión, nos abstenemos de desarrollar este interesante tema, que sobresale a la temática propuesta en esta meditación. Hemos abordado la temática en: (Garrido-Periñán, 2015b: 302-320).

${ }^{18}$ Nótese lo que dice Heidegger (2002: 271): "Perdido en la opinión pública del uno y en su habladuría, el Dasein, al escuchar al uno-mismo, no oye su propio sí-mismo". ["Sich verlierend in die Öffentlichkeit des Man und sein Gerede überhört es im Hören auf das Manselbst das eigene Selbst"].

${ }^{19}$ El uno ayuda por cuanto constituye un horizonte de sentido para el existente, permitiéndole cierta identificación con valores en los que cimienta toda tradición y cultura, pero, al mismo tiempo, este horizonte de pre-comprensión llamado "el uno", impide, para con el existente, un saber de sí radical, ontológico, que atienda a lo más singular y respectivo de su ser. 
un epitome de búsqueda de una atestiguación, en la que su protagonista, en una lucha furibunda, intenta poder-ser-sí-mismo.

\subsection{El Ilamado de la conciencia como primera posibilidad de recuperar la promesa de la decisión propia}

Dijimos casi al comienzo (Cfr. supra: 2.1.) que la conciencia era Gewissen, un estar alerta y un llamamiento a la actuación. ¿Qué nos moverá a buscarnos a nosotros mismos en el modo de recuperar la decisión? La "voz de la conciencia" [Stimme des Gewissens]. En la novela, podemos observar cómo, aunque el protagonista sempiternamente está cuestionando las cosas con las que se enfrenta, carece de esta voz de la conciencia. Esta es la razón de que la voz de la conciencia no sea entendida como una voz de una instancia superior, cuya finalidad sea la materialización de una intervención en nuestro fuero interno con el fin de movernos a actuar. Voz de la conciencia, al modo de Heidegger, tiene que ver con un llamamiento a ser nosotros mismos, tomar nuestro ser como "en cada caso mío"20 [Jemeinigkeit]. La conciencia toma aquí el cariz de una promesa que ha tenido que salir mal parada desde la conformación con el uno. Tener conciencia es para el Dasein prometerse una decisión. Del mismo modo, podemos observar, de qué modo la vida de K. se convierte no solo en un proceso, sino en lo que el proceso no deja traslucir: la promesa de salir de la culpabilidad, para, de una vez, volver a vivir. Bien es verdad que Kafka no va a aclarar si esta vuelta a la vida tiene que pasar por el tamiz de la propiedad existencial, si no, más bien, para Joseph K., tomar su vida significa volver al uno heideggeriano; pero aquí, en cambio, para los dos autores, la posibilidad de saberse, de ser consciente, radica en una promesa. De lo que se trata es de re-tener la posibilidad de lo que uno es. Por eso, es muy importante analizar el modo en el que se nos abre la promesa, en este caso, el "llamado" [Ruf] de la conciencia. Del mismo modo que al inicio de Ser y Tiempo, cuando se lleva a cabo la apertura de la estructura del preguntar (Cfr. 2002: 5-8) ${ }^{21}$, Heidegger va a pasar a abrir fenomenológicamente el llamado. Este fenómeno comporta tres sentidos referenciales: uno, "quién" [Wer] es

\footnotetext{
${ }^{20}$ Esta expresión constituye un existenciario, esto es, un modo en el que se realiza la existencia. Apunta a un carácter, de parte de la misma existencia, de individuación -que no de solipsismo- y responsabilidad: el ser que se pone en juego, en cada posibilidad y decisión, es para todo caso el mío, no pudiendo delegar el modo de mi ser a otro existente, o instancia ulterior (Cfr. Heidegger, 2002: 220-300).

${ }^{21}$ Esta división en la manera de entender el fenómeno, no es nueva de Ser y Tiempo, sino que ya fue tematizada, al menos implícitamente en: (2006: 73 -de un modo aun tosco, pues Hei-
} 
el llamado -en este caso el Dasein en su mundaneidad-; dos, el "hacia dónde" [Woraufhin] del llamado -aquí sería la posibilidad de una decisión propia por parte del Dasein-; tres, el "qué" [Was] del llamado -que es la nada, el silencio(Cfr. Ibid.: 272-273).

Recordemos que el modo del ente Dasein vive entregado y afectado por aquello que se le presenta. El llamado que se le presenta no le permite al Dasein salir de $s^{i 22}$, pues éste apunta a algo que, aunque no lo sepa, es él mismo de un modo radical, ontológico. De ahí que todo llamado implique un "comprender el llamado" [Anrufverstehen] y un "querer tener conciencia" [Gewissenhabenwollen]. En qué sentido lo apuntalaremos más adelante. Por ahora, recuérdese que el Dasein es un modo de ser entregado y radicado en el mundo, sin la posibilidad de salida alguna, de huida. Porque incluso en el estado impersonal, el Dasein sabe de sí mismo (Cfr. infra.: 4$)^{23}$.

\subsection{El Ilamado como quiebre mundano del Dasein y la posibilidad de recuperar la lejanía de su posibilidad}

No nos dejemos engañar: en la posibilidad de un ser consciente al modo ontológico hay siempre sufrimiento. Jospeh K. está a lo largo de la novela sufriendo, angustiado, confuso, casi acéfalo. Esto se debe a que todo llamado comporta un Dasein "quebrado" [Bruch]. La novela kafkiana lo ha reflejado muy bien, sobre todo en la descripción de una sociedad burguesa dominada por el sin sentido burócrata, por el proceso de tramitaciones superfluas, banales, y lo que es peor: en la alienación de individuos, como es el caso del pintor supuestamente intempestivo y bohemio, que vive en una vivienda, además de pobre, anexa al juzgado. Todos parecen ser partes de un sistema que no conoce a nadie, que los trata como nadie, es decir, como uno. El llamado ${ }^{24}$ de la conciencia que está exponiendo Heidegger, como promesa ante la posibilidad de llegar a ser lo que uno es, tiene necesariamente que resultar doloroso, porque de lo que se trata es de un acceder

\footnotetext{
degger coloca 12 momentos estructurales- y 1979: 194 ss. -aquí Heidegger ya sí coloca los 3 momentos estructurales presentes en su opus magnum-).

${ }^{22}$ Salir de sí, entendido no extáticamente, sino como modo de huida.

${ }^{23}$ Donde se versa sobre el carácter auto-referencial del ser del Dasein.

${ }^{24}$ Nota bene, estas referencias en torno al llamado que hace Heidegger: "machacar" [Stoß], "sacudir" [Aufrütteln]. El "llamado" apunta, en todo caso, a un quiebre, una retorsión, un aplastamiento, un sufrir.
} 
a lo velado por el uno: nuestra "mismidad" 25 [Selbstheit]. Podríamos decirlo con más contundencia: el llamado es un modo de apertura del existente, que lo pone ante la posibilidad de una "transparencia" [Durchsichtigkeit] ante su existencia.

Pudiera parecer, sin embargo, que el cariz ontológico de este llamado sería muy similar a la llamada mística, del Dios que reclama la acción piadosa al creyente (Cfr. Garrido-Periñán, 2017b: 651-674). Para aclarar este punto, en nuestra opinión, debemos ser muy cuidadosos. Heidegger mismo se presta a la confusión: "En la tendencia a abrir de la llamada yace el momento de choque, de repentina sacudida. Se llama desde la lejanía hacia la lejanía. La llamada alcanzará al que quiera ser re-tornado" (2002: 271) ${ }^{26}$. Es de vital importancia dilucidar de dónde proviene esa lejanía. ¿Viene de una transcendencia divina? ¿viene del ser, pero, entonces, el ser es un trascendental al modo kantiano, esto es, en tanto consecuencia de un apriorismo trascendental? Creemos que tal problemática hay que ponerla en cuestión con esto que dice Heidegger al inicio del opus magnum: "Lo ónticamente más cercano y conocido es lo ontológicamente más lejano, desconocido y constantemente pasado por alto en su significación ontológica" (Ibid.: 43) ${ }^{27}$. La lejanía es lo ontológico, es decir, el dominio de la posibilidad que se contrapone a la necesidad. El Dasein es, ante todo, un ser-posible. El ser propio del Dasein no deja de ser una posibilidad" ${ }^{28}$. Posibilidad es aquí "poderser" [können-sein], finitud. Como tal posibilidad, emanada del mismo ser del Dasein, está como in nuce en la misma existencia, no viene de afuera, no queda incorporada por un don. Tan radicalmente el llamado es una posibilidad que no dice nada ${ }^{29}$, no nos otorga un contenido existencial para vivir conforme a él. El llamado, por tanto, lo que abre es la posibilidad de la Posibilidad(es) en

\footnotetext{
${ }^{25}$ Para una explicitación de la manera en la que vamos a entender esta mismidad (Cfr. infra.: 4).

26 "In der Erschließungstendenz des Rufes liegt das Moment des Stoßes, des abgesetzten Aufrüttelns. Gerufen wird aus der Ferne in die Ferne. Vom Ruf getroffen wird, wer zurückgeholt sein will”.

27 "Das ontisch Nächste und Bekannte ist das ontologisch Fernste, Unerkannte und in seiner ontologischen Bedeutung ständig Übersehene".

${ }^{28} \mathrm{La}$ posibilidad es siempre fundamento de la necesidad, tal y como se recoge en el Curso de 1919, denominado "Semestre por necesidades de Guerra" [Kriegnotsemester]. Nótese lo que se dice allí (1999: 91): "Todo lo que es real puede mundear, pero no todo lo que mundea necesita ser real”. [“Alles, was real ist, kann welten, nicht alles, was weltet, braucht zu sein”]. Mundear es aquí lo ontológico, la referencia pre-teorética que soporta el sentido del mundo. 29 "El llamado mismo no dice nada, no proporciona ninguna referencia sobre los acontecimientos del mundo, no tiene nada que relatar". [Der Ruf sagt nichts aus, gibt keine Auskunft über Weltereignisse, hat nichts zu erzählen”]. (Heidegger, 2002: 273).
} 
la que consiste nuestra vida ${ }^{30}$. Se entiende que Heidegger la considere en tanto "pre-vocar (anticipadamente) hacia delante" [vor-(nach-vorne-Rufen)] (Cfr. 2002: 276).

Tenemos que mostrarnos cautos y seguir pensando el modo de ser del llamado. Pero apenas nótese que el llamado nos pone ante una negatividad, una nada, una nihilidad. Lo veremos más adelante.

\subsection{El Ilamado como desvelamiento de la inhospitalidad de la nihilidad de la existencia}

Recuérdese que Joseph K., sin esperarlo, un día al despertarse, es acusado de haber realizado algo que, por mor de los policías que invaden su casa, ha de ser punitivo, mover a la culpa. La voz del llamado arremete al Dasein, el Dasein se encuentra abierto y dispuesto a ella, sin intervención de una disquisición volitiva, racional. Justo como el protagonista de la novela kafkiana, se ha tenido que producir un quiebre en el entramado significativo-mundano para que, tanto K., como el Dasein heideggeriano, se den de bruces con algo que son ellos mismos, pero que, en un principio, no sabían de su existencia. Lo que se le abre al Dasein, en la precariedad apocalíptica de su ruptura con la cotidianidad y el uno, es, precisamente, el encontrarse en el "estado de yecto" [Geworfenheit], siendo en el mundo. El encontrarse con el llamado resulta de una liberalización afectiva de su "estado de arrojamiento" 31 [Geworfenheit], un ser arrojado que, como "temple anímico" [Stimmung], es cerrado como tal, a causa de la tendencia del Dasein a ser reflejo del mundo en el que vive y, por ende, no pensarse como posibilidad, sino como cosa, ente ${ }^{32}$. El llamado surge, entonces, de la misma constitución

${ }^{30}$ Compárese con lo dicho en torno a la muerte (2002: 250): "La muerte es la posibilidad de la radical imposibilidad de existir". En este caso, para decirlo afirmativamente, el "llamado" lo que hace es desvelar que la existencia consiste, stricto sensu, en la posibilidad y en la proyección de ser conforme a esa posibilidad.

${ }^{31}$ Optamos por traducirlo de manera dual, recogiendo las traducciones realizadas por José Gaos y Eduardo Rivera.

${ }^{32}$ Esta tendencia casi natural que tiene el Dasein a comprenderse desde el estado de interpretado del mundo en el que vive es resaltada en (2002: 15-16): "El Dasein tiene, más bien, con arreglo a su correspondiente modo de ser, la tendencia a comprender su ser desde aquel ente con el que esencial, constante e inmediatamente se relaciona en su comportamiento desde el mundo. En el Dasein mismo y, de este modo, en su propia comprensión de ser, hay algo que más adelante se dejará ver como la refracción ontológica de la comprensión del mundo sobre la interpretación del Dasein". ["Das Dasein hat vielmehr gemäß einer zu ihm gehörigen Sein- 
del existente que estriba en ser-arrojado en el mundo mientras vive, en carecer de centro, fundamento por el que comenzar a ser, pensarse, identificarse. Por esta razón, el existente o Dasein, siendo un "proyecto arrojado" [geworfener Entwurf], no es un proyecto "flotante en el vacío" [freischwebend], está al máximo cargado de mundo y facticidad. El llamado no hace más que poner al Dasein en su facticidad ontológica más originaria. Esta forma, aunque en su paradójica expresión, es llamada por Heidegger "inhospitalidad" 33 [Unheimlichkeit], y es definida en tanto estructura ontológica del ser del Dasein, una estructura basada en la carencia de hogar. Que se carezca de hogar no ha de mentar que el Dasein no tenga mundo, ni que K. sea un apátrida, justo lo contrario, carecer de hogar significa que antes de habitar un mundo, el existente es definido desde y como "poder-ser" [können-sein].

No hay que olvidar que la inhospitalidad de la existencia está ligada, al menos en Ser y Tiempo, con el existenciario total, que compendia el mismo ser del existente: el "cuidado"34 [Sorge]. Que el Dasein carece de hogar significa también el imperativo de tener que "cuidarse a sí mismo" [Selbstsorge], de los demás [fürsorge] y del mundo circundante ${ }^{35}$ [besorgen] (Cfr. 2002: 277). El cuidado, aún en sus tres modalidades, denota la preeminencia de la posibilidad como modo de ser del Dasein sobre la objetividad, la necesidad o la realidad. Por esta razón, el estado de arrojamiento es sinónimo de tener que tomar la (nuestra) existencia como una posibilidad que necesita ser ejecutada "en cada caso" 36 [Jeweiligkeit]. Heidegger, a

sart die Tendenz, das eigene Sein aus dem Seienden her zu verstehen, zu dem es sich wesenhaft ständig und zunächst verhält, aus der 'Welt'. Im Dasein selbst und damit in seinem eigenen Seinsverständnis liegt das, was wir als die ontologische Rückstrahlung des Weltverständnisses auf die Daseinsauslegung aufweisen werden”].

${ }^{33}$ Es de vital importancia este existenciario, pues mueve al Dasein para que se encuentre con su propio ser, a través de la angustia. Véase lo que dice Heidegger en (2002: 263): "La angustia es un estar en lo inhóspito". ["In der Angst ist einem unheimlich”]. También (Ibíd.: 188 y 276).

${ }^{34} \mathrm{Tal}$ es la importancia del cuidado en (2002: 252): "El cuidado es el título ontológico para la totalidad del todo estructural del Dasein". [Sorge ist der ontologische Titel für die Ganzheit des Strukturganzen des Daseins"].

${ }^{35}$ La mismidad apunta a un fenómeno temporal en las dimensiones prácticas del mundo entorno, mundo compartido y, por último, mundo de sí mismo ( $C f r$. Heidegger, 1995: 11, 13, 103, 187-188, 192, 204, 211, 212-214, 227-228, 228, 232, 237-241, 245-247, 253255, 298, 331-332; 1988: 29 y 102; 1992: 54-58, 342, 348, 440-441, 442; 1976: 236, 338-344, 344-347 y 1975: 194, 224-228, 242, 249, 394-395 422, 425).

36 Término no empleado en Ser y Tiempo, al ser reemplazado por Jemeinigkeit. En este caso, jeweilig se traduce por "en cada caso", "cada vez", en virtud de la raíz alemana weile-, esto es, "instante", "momento". Nosotros hemos analizado la relación de este concepto en la obra de 
su modo y atendiendo a las resonancias del llamado de la conciencia, de su voz, traduce esta inhospitalidad como "estado de silenciado" [Verschwiegenheit] (Cfr. Ibid:: 277). Entre tanta algarabía, sobre tantas y tantas habladurías [Gerede], el "llamado" lo que hace es "retro-vocar" [zurück-rufen] al estado de silenciado, donde el poder-ser en el mundo mismo acontece, arremete al Dasein. Lo que se muestra en la retro-vocación de la existencia es nada, es pura "nihilidad" [Nichtigkeit] (Cfr. Ibid.: 286). La nihilidad es lo que permite la conservación de la posibilidad en la que estriba la existencia. Como se ve en la vida de K., en su ignorancia ante lo que se le acusa, es esta nihilidad la que constituye su ser, pero él no lo sabe, y busca, busca sin cesar. Y nada encuentra.

\subsection{Culpabilidad y nihilidad: primeros pasos para Ilegar a ser sí mismos}

Si es verdad que tanto el Dasein como K. son culpables, tendríamos que explicitar qué tiene que significar tal aserto. En alemán culpa se dice Schuld y mienta en español tanto culpa como culpabilidad, en el sentido de "deber algo", de "ser culpable de algo" o, del mismo modo, como por ejemplo cuando se dice "estar en deuda" [sein in der Schuld]. En este sentido, está hablando Heidegger de una culpa ontológica, que hace posible el modo cotidiano de deber-algo, estar en deuda: "El ser culpable no es el resultado de un endeudamiento, sino al revés: éste solo es posible solo la base de un originario ser-culpable" (2002: 284) ${ }^{37}$. Este ser culpable, al modo ontológico, es recogido con esta abstracta consideración: "el desde dónde del retro-vocar hacia..., es el hacia donde del retro-vocar" (Ibid.: 286) ${ }^{38}$. ¿A qué se está refiriendo Heidegger en este aparente juego de palabras un tanto confuso? En nuestra opinión, esta última definición, no hace más que explicitar lo que hemos mantenido hasta ahora en nuestra meditación: el "llamado" de la conciencia lo que hace es ponernos ante la inhospitalidad de nuestro ser-en-el-mundo, entendido como ser, estar, pensarnos, en y desde la posibilidad, y, por otro lado, esta inhospitalidad existencial, a la vez, constituye el

Heidegger en: (Garrido-Periñán, 2016a: 275-296), al socaire del concepto paulino de parousia. La relación, además, de Jeweligkeit con el concepto griego kairos es evidente, por cuanto manifiesta el carácter temporal de la existencia, que es propia, si y solo si, en el momento oportuno de una apropiación, proyectada como modificación del estado cotidiano, el existente consigue anteponerse a su tendencial posibilidad a la caída.

37 "Das Schuldigsein resultiert nicht erst aus einer Verschuldung, sondern umgekehrt: diese wird erst möglich auf Grund eines ursprünglichen Schuldigseins".

38 "Das Woher des Rufens im Vorrufen auf ist das Wohin des Zurückrufens". 
horizonte indeleble en el que consiste la existencia del Dasein, nuestra existencia. Por ese motivo, el "llamado" surge desde sí mismo, desde la propia existencia y desde el propio modo de ser del Dasein, sin necesidad de presuponerlo, inventarlo o acudir a una instancia ulterior. Por esta razón, solo la fenomenología puede acudir a su llamada (Cfr. supra.: 1) ${ }^{39}$.

El "desde dónde" [Woher] coincide con el "hacia dónde" [woraufhin], es decir, que el fundamento del Dasein es sí mismo una nihilidad y que el proyecto que constituye su existencia, en tanto posibilidad, está signado, del mismo modo, por la nihilidad, comprendida como "estado de yecto/arrojado" [Geworfenheit] e "inhospitalidad" [Unheimlichkeit]. Pero, entonces, ¿no es esto un nihilismo negativo al estilo de Nietzsche? ¿no está Heidegger siendo un nihilista en la modalidad del resentimiento? En ningún caso hay que entender la nihilidad que surca la existencia como una cosa o un ente. Más bien, la nihilidad es una "indicación formal" ${ }^{40}$ [formale Anzeige] que nos pone ante la advertencia de ser, actuar, hacer, si solo si somos siempre poder-ser. Puede decirse de otro modo: como no somos algo cósico, definidos en tanto ente, como las propiedades que puede tener un determinado objeto ${ }^{41}$, no podemos obtener una definición total, omnímoda, de nuestra existencia. Por tanto, estamos signados por una nihilidad, que es una promesa, que nos conmueve a actuar y ser. Nihilidad quiere mentar una indicación para que el Dasein, a partir de la pérdida de sí, en el uno impersonal, sea el que es. Culpabilidad ontológica es pues inconformidad con el entramado hermenéutico y social del uno (Cfr. Heidegger, 2002: 287). Ser culpable significa, entonces, el primer paso para llegar a ser sí mismo.

\section{El camino para un descubrimiento del sí mismo del Dasein: comprensión, responsabilidad, estado de resuelto y la situación fenomenológica}

Hasta ahora hemos emprendido una tarea puramente negativa, al exponer un análisis sobre cómo arremete la culpa al ser del existente en su situación más nuda. Es hora, no obstante, de adentrarnos en las posibilidades de que un determinado existente, partiendo de la culpa ontológica que motiva su vida, pueda

\footnotetext{
39 La fenomenología trabaja con modos de ser, no con la quiddidad de la cosa.

${ }^{40} \mathrm{La}$ indicación formal hace mención a las referencias hermenéuticas, indicativas-ejecutivas, que surcan la existencia. No son nexos normativos, sino formales, modos de ser (Cfr. Heidegger, 1995: 16).

${ }_{41}$ Piénsese en el ejemplo de la "cera" que pone Descartes en sus Meditaciones (Cfr. 1977: 23-30).
} 
llegar a entenderse, ser sí mismo. Justamente lo que en la novela de Kafka su protagonista no llega a ser jamás.

\subsection{La transformación de la culpa en comprensión y el adelantarse a la posibilidad como responsabilidad}

Cualquier ser humano puede sentirse culpable y deudor, mas luego seguir en sus treces, cometer delito, vivir impropiamente, hasta olvidar que es culpable. Tal indicación debe hacernos pensar que el procedimiento de un análisis de la culpabilidad existencial, por sí mismo, es insuficiente. El sentirnos culpables no nos garantiza una transformación en nuestro modo de ser. Al menos, para ser comedidos, no nos lo garantiza de forma natural y a priori. Sabemos, por la lectura de la novela de Kafka, que el autor checo no entra en la consideración filosófica sobre cómo su protagonista puede llegar a ser él mismo. En este caso, aunque parezca sorprendente, sí lo hace Heidegger. Él lo llama ser "responsable" [verantwortlich] (Cfr. 2002: 288). La responsabilidad es una consecuencia de lo que denomina "querer-tener-conciencia" [Gewissen-haben-wollen]. Todo esto es posible porque, además de encontrarse con el "llamado", el Dasein puede comprenderlo (Cfr. Ibid:: 184) ${ }^{42}$. No hay una frontera, ni un abismo, entre padecer y comprender, toda comprensión es una comprensión-afectiva. Por esta misma razón, la nihilidad expresada por el ontológico ser-culpable del Dasein tiene que ser asumida por el existente, es decir, comprendida:

El Dasein proyecta, en cuanto comprender, su ser hacia posibilidades. Este comprensor ser para posibilidades es en sí mismo, por la repercusión que tienen sobre el Dasein en tanto que abiertas, un poder-ser. El proyectarse del comprender tiene su propia posibilidad de desarrollo. A este desarrollo del comprender lo llamamos interpretación (Ibid. $)^{43}$.

\footnotetext{
${ }^{42}$ La comprensión es un modo del "Ahî" del Dasein, un modo de apertura de su ser.

43 "Das Dasein entwirft als Verstehen sein Sein auf Möglichkeiten. Dieses verstehende Sein zu Möglichkeiten ist selbst durch den Rückschlag dieser als erschlossener in das Dasein ein Seinkönnen. Das Entwerfen des Verstehens hat die eigene Möglichkeit, sich auszubilden. Die Ausbildung des Verstehens nennen wir Auslegung".
} 
Comprender quiere decir aquí, entonces, anticipación, anticiparse-a, "adelantarse hasta la posibilidad" [Vorlaufen in die Möglichkeit]. Para nosotros, ser responsable significa adelantarnos a nuestro ser culpable, a nuestra nihilidad, asumirla y actuar conforme a esta máxima. Pero, ¿no habíamos dicho que lo que abre la culpabilidad es una nihilidad? ¿cómo se puede comprender una nihilidad? ¿Acaso es esto posible? Es posible, según Heidegger, porque lo que abre el "llamado" es la existencia misma, esto es, la disposición a tener que comprender posibilidades y ser conforme a estas mismas posibilidades. Cuando el Dasein se comprende desde la posibilidad radical de su existencia, surge la responsabilidad, que es un modo de ser-propio en la misma existencia. Este modo de propiedad existencial es definido como "estado de resuelto" [Entschlossenheit] (Cfr. Ibid.: 299). De qué modo lo veremos a continuación.

\subsection{El estado de resuelto y la tendencia a la auto-comprensión y auto-proyección de la comprensión}

El estado de resuelto es una modalidad de apertura del ser del Dasein óptima, sobresaliente, pues abre el "Ahî" $[D a]$ de una forma plena, en la medida en que se obtiene la inhospitalidad del ser-en-el-mundo (Cfr. Heidegger, 2002: $263)^{44}$ como (des)fundamento de su ser. Heidegger lo dice a su manera en la explicitación de que el estado de resuelto solo existe en tanto "resolución autocomprensiva y auto-proyectiva" [verstehendsich-entwerfender Entschluß] (Cfr. Ibid.: 298). En el argot heideggeriano estas formulaciones son muy habituales, pero, más allá de su elaboración abstracta y casi barroca, no por ello es una banalidad. Quedémonos, mientras, con que el estado del resuelto apunta a un "auto-", tanto a la auto-comprensión como a la auto-proyección. ¿Qué significa semejante cosa? Significa que el estado de resuelto pasa por un descubrimiento de un sí mismo, es auto-referencial. Cuando el Dasein se comprende proyectivamente desde y con la posibilidad que enmarca su ser, el "mundo entorno" [Umwelt] y el "mundo compartido" [Mitwelt] se transmutan, produciéndose una modificación del horizonte de sentido en el que acontece todo, en el que se da todo. De este modo, en nuestra opinión, se tendrá que entender el famoso "dejar-ser" [sein-lassen]. Dejar-ser no significa más que perseverar la posibilidad como preeminente modo de ser de la existencia. Desde este horizonte es posible "llegar a ser libre" [Freiewerden] para ser responsable, si ser responsable es, entre

\footnotetext{
${ }^{44}$ Hemos abordado la relevancia de la inhospitalidad ontológica, en relación con la obra de arte, en Garrido-Periñán (2015b: 283-312).
} 
tanto, decidirse a ser-libre, esto es, ser posible desde un proyectar arrojado que tiene que comprenderse, en cada caso, como poder-ser.

Este modo ontológico de ser responsable ha sido abierto al socaire del análisis de la culpabilidad como originario modo de ser del Dasein, en la medida en que solo puede ser responsable quien se asume como posibilidad y entiende, se comporta, ejecuta su relación con el entorno y sus semejantes, desde este horizonte comprensivo. Todavía, en cambio, no ha sido abierta la cuestión de en qué modo el estado de resuelto tiene que ver con un estado de propiedad de la existencia y su temporalidad. Esto tendrá que ver con la siguiente apreciación: lo abierto por el estado de resuelto es la "situación" [Situation] en la que se dan las cosas y se produce el principio de acción humana, para consigo mismo y para con sus semejantes.

\subsection{El estado de resuelto y la apertura ejecutiva de la situación}

El estado de resuelto es, por tanto, la condición de posibilidad para que haya algo así como una situación. La situación hace mención al ámbito originario donde las cosas se dan, obtienen una "proximidad" [Nähe] y una "distancia" [Wei$t e$. La situación cumple la función del espacio ontológico dada por Heidegger en la I Sección (Cfr. 2002: 110-113) ${ }^{45}$, esto es, tiene que ver con la conformación del "lugar" [Ort] y con su asignación [Ortzuweisung] (Cfr. Heidegger, 1988: 41 y 86), al ámbito de emplazamiento donde los entes se acogen a un horizonte de sentido, donde, también, aparece, como otro igual que yo, la alteridad, mentada con el "ser-con" [Mit-sein] (Cfr. Ibid.: 114-129); pero, en este caso, una vez abierta la veda de la resolución del Dasein, anclada en la inhospitalidad de su existencia, la situación va abrir la radical posibilidad de ser sí mismo. Aquí es conveniente advertir que al uno también le pertenece la apertura de una situación, aunque esta sea una "situación general" [allgemeine Lage] (Cfr. Ibid:: 299), a saber, una situación incapaz de concretar una atestiguación para que el existente sea sí-mismo, y asuma la posibilidad como originario modo de ser, de su ser. ¿Qué se le abre al Dasein en su situación radical para ser sí mismo? Otra vez debemos ser cautos, pues de ningún modo la situación puede abrir un qué, una cosa, un contenido que tenga el carácter de ousia. La situación abre un modo de ser en que tienen lugar "referencias" [Bezügen] que, en cada caso,

\footnotetext{
${ }^{45}$ Nótese que dice Heidegger en el curso de 1919 (1999: 68): “... proximidad y distancia no
} son un cuánto”. [“...Nähe und Weite sind nicht ein Wieviel”]. 
tienen que ser llevadas a cabo por el Dasein mientras viva. La situación radical de la que estamos hablando, emplazada por la resolución del Dasein, le abre a éste su propia, e "intransferible", situación, como del mismo modo lo hacía el "serpara-(vuelto-a)-la-muerte" [sein-zum-Tode]. Recuérdese: "nadie puede tomarle a otro su morir" (Ibid.: 240) ${ }^{46}$. ¿Podría el existente, una vez abierta su situación radical, elegir si ejecutarla, o no? Aquí Heidegger es muy tajante y explicita una respuesta categórica: no. ¿Por qué? El estado de resuelto, como un modo de desvelamiento óptimo del "Ahî" $[D a]$ que sostiene al Dasein, fue posibilitado por una toma de conciencia comprometida con su propia elección, en una "propiaelección" [eigene Wahl], materializada en lo que hemos denominado "comprender el llamado" [Anrufverstehen] (Cfr. supra.: 2.3). De suerte que esta comprensión es siempre comprensión de una posibilidad, posibilidad que a la vez somos nosotros mismos. Por esta razón, desde este horizonte, comprender es elegirse a sí mismo, ser, actuar, "obrar" [Handeln] (Cfr. Ibid.: 300 ss.) ${ }^{47}$.

En virtud de lo dicho, podemos decir, entonces, que el estado de resuelto es, per se, resolutivo, practico, ejecutivo. No hay una "resolución" [Entschluß] teórica, como el "tomar nota" [Kenntnisnahme], sino ejecutiva [Vollzug].

\section{Conclusión: el énfasis del carácter auto-referencial, la temporalidad finita del Dasein y el conócete a ti mismo como forma de saber de sí}

La mismidad ha quedado atestiguada como resguardo de la posibilidad, en un retrotraer al existente ante la posibilidad, en la mayoría de los casos, menoscabada ante la realidad, la objetividad, o, para decirlo con la fenomenología, por la actitud natural. Que sea referencia para el Dasein su propio modo de ser, implica que, en su trato con el ente intramundano y con los demás existentes, en cada caso, este Dasein se comprende a sí mismo. ¿Qué significa que se comprende a sí mismo? Podríamos decirlo tal que así: en cada una de las posibilidades que enmarcan nuestra vida, nuestro propio ser, en cada ocasión, "tiene que ser" [zusein], no puede no-ser; más aún, ¿qué y quién somos (soy)? Según Heidegger, somos posibilidad, entendida como un proyecto arrojado-comprensivo, definidos en tanto "comportarse" [sich-verhalten] (Cfr. Garrido-Periñán, 2017a: 68-81 y

\footnotetext{
46 "Keiner kann dem Anderen sein Sterben abnehmen".

${ }^{47}$ Obrar en el sentido de hacerse cargo del cuidado que surca nuestro ser. Por tanto, es un obrar ontológico, previo a la distinción de acción teórica o práctica.
} 
2016b: 63-73), un comportarse que, por un lado, tiene que asumir su pérdida de fundamento, su des-centralidad, y, por otro, asumir lo que es mediante la comprensión del sentido de su ser. Al no ampararse en discursos que "substancialicen" la subjetividad, Heidegger no puede más que partir de ese estado relacional que conformaría el propio ser del Dasein. En cada caso, de una manera natural e inercial, somos el uno-mismo. Tenemos que recuperarnos a nosotros mismos, paradójicamente, para llegar a ser lo que somos. En este caso, la "temporalidad del Dasein" 48 [Zeitlichkeit] juega un papel muy importante, sobre todo en la consideración del Dasein como ser-relacional. Pues bien, si lo que somos es relación, comportarse, y, además, un comportarse proyectivo-comprensivo, tendremos que decir que nos definimos a partir de "referencias" [Bezügen] que, "en cada caso" [Jeweiligkeit] tienen que ser ejecutadas [Vollzug], tal como vimos en la comprensión de la resolución como sumamente ejecutiva (Cfr. supra.: 2.1). No somos más que un proyecto definido en tanto posibilidad comprensiva. La temporalidad se inscribe en el propio ser del Dasein, porque la temporalidad es una modalidad de ejecución de esas referencias hermenéuticas que forman nuestro ser-en-el-mundo, donde pivota nuestra auto-identificación, la ciudad donde vivimos, nuestra tradición. Esta temporalidad del Dasein, conforme al espíritu expuesto en Ser y Tiempo, es posible trascendentalmente si solo si se comprende como modo de temporalización del ser [Temporalität]. Esto se cumple, con Heidegger, en la medida en que el Dasein es definido como el "ahî" $[D a]$ del ser. Pero lo que nos importa a nosotros es la indicación de que, en definitiva, el ser del Dasein está marcado por la temporalidad. Somos tiempo significa, entre tanto, que no podemos pensarnos si no es a través de un horizonte temporal, por cuanto somos-sido ${ }^{49}$ como referencias ejecutoras.

Heidegger, por lo demás, se está posicionando aquí junto a Sócrates, hermanado con la indicación délfica: ¡conócete a ti mismo! Y con Kant: ¡atrévete a

\footnotetext{
${ }^{48} \mathrm{Al}$ contrario que el Prof. José Eduardo Rivera, que traduce "temporalidad" por Temporalität y "temporeidad" por Zeitlichkeit, preferimos no atender a tal división, pues, en cualquier caso, ambos fenómenos, desde el plano de la obra cumbre heideggeriana, vienen a manifestar algo idéntico, sobre todo, si nos ceñimos a unas de las hipótesis vertidas en el Tratado: el Dasein es el ente que trasluce y transparenta, de algún modo, el darse mismo del ser. No hay darse del ser si no pasa por el Dasein. Por tanto, ambos conceptos deben entenderse como horizontes de tiempo, esto es, en tanto temporalidad. Lo que sucede es que la palabra Temporalität tiene una finalidad trascendental, pues de lo que se trata es de ganar el horizonte general de presentación del ser del ente. Pero, no lo olvidemos, este horizonte general, de presentación del ser del ente mismo, es la existencia, esto es, Dasein.

${ }^{49}$ Recuérdese lo dicho de la importancia de la facticidad, ejemplarizado en el caso de Joseph K. (Cfr. supra.: 2.1).
} 
pensar! Si el existente quiere ser sí mismo, tiene que conquistar este sí mismo, en una recuperación por ser la temporalidad que sido-seremos. Y, ¿qué temporalidad es el Dasein? Finitud. Tenemos que conocernos a nosotros mismos como seres finitos en la medida en que, en cada caso, tenemos que ser, ejecutarnos, comprendernos, como mortales. Comportarse desde la posibilidad con la posibilidad, en tanto nuestro ser lo define un poder-ser entregado a tener que decidir(se). Es la forma en que la finitud, menoscabada y perdida en el uno-impersonal, vuelve sobre sí misma, para que el existente tenga una posibilidad de ser propio, es decir, ser-sí-mismo, su mismidad. Es la respuesta que da Heidegger, en nuestra opinión, al pensamiento moderno, muchas veces enclavado en una egodicea, incapaz de pensar el mundo, y al ser humano, si no es como ego-cogito.

\section{Bibliografía}

Carman, Taylor (2003). Heidegger's Analytic. Interpretation, Discourse, and Authenticity in Being and Time. Cambridge: Cambridge University Press.

Descartes, René (1977). Meditaciones cartesianas con objeciones y respuestas. Trad. Vidal Peña. Madrid: Alfaguara.

Escudero, Jesús A. (2016). Guía de lectura de Ser y Tiempo. Vol. 2. Barcelona: Herder.

Gadamer, Hans-Georg (1983). "Die Marburger Theologie". Heidegger Wege, Tübingen: J.C.B Mohr.

-(1987). "Praktisches Wissen". Neuere Philosophie I: Hegel, Husserl, Heidegger. Gesammelte Werke, vol. 3. Tübingen: J.C.B. Mohr, pp. 244-247.

GARrido-Periñán, Juan José (2012). "Crítica de la razón del comenzar: esbozos hacia una filosofía del nacimiento". Eikasia: Revista Internacional de filosofía, 44, pp. 99-112.

-(2015a). "Carta sobre el Humanismo: consideraciones del "ahí" del ser. ¿Es posible habitar el claro del ser?”. Eikasia: Revista Internacional de Filosofia, 61, pp. 302-320.

-(2015b). "El horror a ti debido: lo inhóspito en el origen de la obra de arte de Martin Heidegger”. Problemata: Revista Internacional de Filosofía 6 (2), pp. 283-312.

-(2016a). "Intentos de una apertura fenomenológica de lo religioso desde el curso Introducción a la fenomenología de la religión de Martin Heidegger: el descubrimiento de la temporalidad como sí mismo del Dasein”. Estudios Filosóficos, vol. LXV, núm. 189, Instituto Superior de Filosofía de Valladolid, pp. 275-296. 
-(2016b). "Ser-en-el-cuerpo: tentativas para un esclarecimiento sobre cómo aparece un cuerpo. En y mundo". Daimon: Revista Internacional de Filosofía, Universidad de Murcia, Suplemento 5, pp. 63-73.

-(2017a). "Ciencia originaria de la vida: sophrosyne, en, mundo y Dasein". Estudios de Filosofía 55, Universidad de Antioquía, pp. 68-81.

-(2017b). "La experiencia de la religiosidad: caminos fenomenológicos en busca de la mismidad del Dasein. Heidegger y la fenomenología de la religión". Revista Portuguesa de Filosofía 73(2), pp. 651-674.

Hegel, Georg-Wilhelm (1980). Phänomenologie des Geistes. Gesammelte Werke, IX, Meiner Verlag, Hamburg.

Heidegger, Martin (1975). Die Grundprobleme der Phänomenologie. II Abteilung, Band 24, Frankfurt a.M.: Vittorio Klostermann.

-(1976). Wegmarken. Gesamtausgabe, I. Abteilung, Band 9, Frankfurt a.M.: Vittorio Klostermann.

-(1977). Holzwege. I. Abteilung, Band 5, Frankfurt a.M.: Vittorio Klostermann.

-(1979). Prolegomena zur Geschichte des Zeitbegriffs. II. Abteilung, Band 20, Frankfurt a.M.: Vittorio Klostermann.

-(1983). Die Grundbegriffe der Metaphysik. Welt-Endlichkeit-Eisamkeit. II. Abteilung, Band 29/30, Frankfurt a.M.: Vittorio Klostermann.

-(1988). Ontologie (Hermeneutik der Factizität). II Abteilung, Band 63, Frankfurt a.M.: Vittorio Klostermann.

-(1992). Platon: Sophistes. II. Abteilung, Band 19, Frankfurt a.M.: Vittorio Klostermann.

-(1995). Phänomenologie des Religiösen Lebens. II. Abteilung, Band 60, Frankfurt a.M.: Vittorio Klostermann.

-(1999). "Die Idee der Philosophie und das Weltanschauungsproblem (Kriegsnotsemester 1919)". Zur Bestimmung der Philosophie. II. Abteilung, Band 56/57, Frankfurt a.M.: Vittorio Klostermann, pp. 3-117.

-(2002): Sein und Zeit. Tübingen: Max Niemeyer.

-(2006). Einführung in die phänomenologische Forschung. II. Abteilung, Band 17, Frankfurt a.M.: Vittorio Klostermann.

Hüвsch, Stefan (1995). Philosophie und Gewissen. Beiträge zur Rehabilitierung des philosophischen Gewissensbegriff. Göttingen: Vandenhoeck \& Ruprecht.

Husserl, Edmund (1959). Erste Philosophie, Zweiter Teil: Theorie der phänomenologischen Reduktion. Husserliana VIII, Den Haag: Martinus Nijhoff. 
-(1966). Zur Phänomenologie des inneren Zeitbewußtsein. Husserliana X, Den Haag: Martinus Nijhoff.

-(1977). Ideen zu einer reinen Phänomenologie und phänomenologischen Philosophie. Erstes Buch: Allgemeine Einführungin die reine Phänomenologie. Husserliana XIX/I, Den Haag: Martinus Nijhoff.

KafKa, Franz (2003). El Proceso. Santa Fé: El Cid Editores.

Kant, Immanuel (2004). Vorlesung zur Moralphilosophie. Vorlesung über allgeimene praktische Philosophie und Ethik, Nachschrift Kaehler. Hamburg: Meiner Verlag.

-(2005). Crítica de la razón pura. Trad. Pedro Ribas, Madrid: Taurus.

SLOTERDiJK, Peter (2001). Eurotaoismo: aportaciones a la crítica cinética a la política. Trad. Ana María de la Fuente, Barcelona: Seix Barral.

Wiemel, Walter (1991). "On the Manifold Significance of Time in the Novel", Phenomenology and Aesthetics: Approaches to Comparative Literature and the Others Arts, Dordrecht/Boston/London: Kluwer Academic Publisher, pp. 17-38.

Recibido : $17 / 04 / 2017$

Aceptado : 14/07/2017

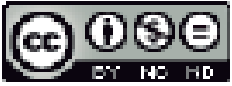

ENDOXA está bajo una licencia de Creative Commons Reconocimiento-NoComercial-SinObraDerivada 4.0 Internacional 